\title{
An Energy-Saving Control Model and Strategy Based on Divided Areas for Intelligent Building
}

\author{
Hongjun $\mathrm{Yu}^{1}$, Chengyu $\mathrm{Ma}^{2}$, Zhifeng Liu ${ }^{3}$ \\ ${ }^{1}$ China Aero-Polytechnology Establishment, Beijing, 100028, China \\ ${ }^{2}$ College of Mechanical Engineering and Applied Electronics Technology, Beijing University of \\ Technology, Beijing, 100022, China \\ ${ }^{3}$ College of Mechanical Engineering and Applied Electronics Technology, Beijing University of \\ Technology, Beijing, 100022, China
}

Keywords: Intelligent building, Control model based on dividing areas, Energy-saving strategies, Temperature and illumination

\begin{abstract}
In order to solve the problem that it is difficult to give consideration to comfort and energy efficiency at the same time, the paper constructs a math model. The model whose parameters consists of indoor and outdoor temperature, illumination and user target values, takes time as a constraint, and then, takes contentment and energy consumption as the targets. Based on the model, the energy-saving strategies and solution which includes four elements is established. The first part is to divide the room to a number of areas and carry out personalized intelligent control. The second part is to considerate difference between time slots and the case whether a man exists in the room. The third part is to introduce favorable outdoor effects through windows and shutters. The last part is to provide manual functions to users. As a result the presented model and methods can satisfy the individual requirements of users, save energy to a certain extent and solve the contradiction between comfort and energy-saving.
\end{abstract}

\section{Introduction}

Building energy efficiency is a question of common concern and attention all over the world[1]. In modern buildings, air-conditioning, lighting systems the largest proportion of energy consumption, but also the greatest potential for energy saving equipment. Statistically, the total energy consumption in the building life cycle, construction of the production process, operation heating, the illumination accounted for $20 \%, 40 \%$ and $40 \%$ [2] respectively, and the use of energysaving building automation system control, can save energy more than $25 \%$. Development of intelligent building automation system[3] is an effective energy-saving measures.

Guangyuan Huang[4] established mathematical model of temperature distribution about environmental temperature. Xueli Zhu, Weigui Qi and Yajun Lu[5] based on the needs of energysaving building heating and characteristics of heating objects, put forward the heating load prediction and predictive control strategy, the process of heating by using the theory of time series analysis of load forecast, gave a predictive control algorithm of the forecast error correction instead of error correction and the heating system-related algorithm for the simulation calculations. Xu Zhang, Suilin Wang [6] studied the structure of the Beijing area office building air conditioning system, operated modes and energy consumption, focused on the effects of indoor temperature on the system, the analysed the energy saving potential of the system, pointed out the root causes of high energy.

\section{System model and analysis of energy saving strategies}

\section{System model}

Assuming the user satisfaction of the temperature environment for $\mathrm{C} 1$, satisfaction of the illumination environment for $\mathrm{C} 2$, user satisfaction is associated with the difference between actual 
environment parameters and user expectations, the relationship between comfort at a moment and indoor environment available by the formula (1) and (2) said.

$$
\begin{aligned}
& \mathrm{C} 1=\mathrm{f}_{\mathrm{c}}\left(\mid \mathrm{T}_{\mathrm{r}}-\mathrm{T}_{\mathrm{e}}\right) \\
& \mathrm{C} 2=\mathrm{f}_{\mathrm{c}}^{\prime}\left(\left|\mathrm{L}_{\mathrm{r}}-\mathrm{L}_{\mathrm{e}}\right|\right)
\end{aligned}
$$

Where, fc is calculated as a function of the temperature of satisfaction, $\operatorname{Tr}$ is the actual indoor temperature, $T_{e}$ is the user desired indoor temperature. $f_{c}^{\prime}$ is calculated as a function of illumination satisfaction, $L_{r}$ is the actual indoor illumination, $L_{e}$ is the user desired indoor illumination.

Assuming that the target setting temperature of the air conditioning is Ts, the target illuminance is Ls, assuming that air conditioner and lamps and lanterns can be well adjusted, the actual control result and set the differences between the values can be ignored, then the formula (1) Tr can be used in place of Ts, the formula (2) Lr in place of Ls, can be used to obtain the formula (3) and (4):

$$
\begin{array}{r}
\mathrm{C} 1=\mathrm{fc}(|\mathrm{Ts}-\mathrm{Te}|) \\
\mathrm{C} 2=\mathrm{f}_{\mathrm{c}}^{\prime}(|\mathrm{Ls}-\mathrm{Le}|)
\end{array}
$$

Assuming that total energy consumption is E, air conditioning energy consumption is E1, lighting energy consumption is E2. Air conditioning energy consumption is related to initial indoor temperature, outdoor temperature and target temperature. Assuming that the period of time no significant change in the outdoor temperature and the air conditioning can be adjusted quickly to temperature adjustment, namely ignore time adjustment, the energy consumption for air conditioning of formula (5):

$\mathrm{E} 1=\mathrm{f}_{\mathrm{e}}^{1}(\mid \mathrm{Ts}-$ Tinit $\mid)+\mathrm{f}_{\mathrm{e}}^{2}(\mid \mathrm{Ts}-$ Tout $\mid)$

Where, $\mathrm{f}_{\mathrm{e}}{ }^{1}$ is calculation function reflect the energy consumption of the initial indoor temperature and the target temperature, $\mathrm{f}_{\mathrm{e}}^{2}$ is calculation function reflect the energy consumption of the outdoor temperature and the target temperature, $\mathrm{T}_{\text {init }}$ is initial indoor temperature, $\mathrm{T}_{\mathrm{s}}$ is target temperature, $\mathrm{T}_{\text {out }}$ is outdoor temperature.

Assuming no lights indoor illumination is $\mathrm{L}_{0}$, the set target illumination is $\mathrm{L}_{\mathrm{s}}$, the energy consumption for lamp of formula (6):

$$
\mathrm{E} 2=\mathrm{f}_{\mathrm{e}}^{\prime}\left(\left|\mathrm{L}_{\mathrm{s}}-\mathrm{L}_{0}\right|\right)
$$

Where, $f_{e}^{\prime}$ is a calculation function on lamp energy consumption.

The total energy consumption: $\mathrm{E}=\mathrm{E} 1+\mathrm{E} 2=\mathrm{f}_{\mathrm{e}}^{1}\left(\left|\mathrm{~T}_{\mathrm{e}}-\mathrm{T}_{\text {init }}\right|\right)+\mathrm{f}_{\mathrm{e}}^{2}\left(\left|\mathrm{~T}_{\mathrm{e}}-\mathrm{T}_{\text {out }}\right|\right)+\mathrm{f}_{\mathrm{e}}^{\prime}\left(\left|\mathrm{L}_{\mathrm{e}}-\mathrm{L}_{0}\right|\right)$.

In summary, the system model can be represented by the formula:

$$
M(C 1, C 2, E): \quad\left\{\begin{array}{l}
C 1=f_{c}\left(\left|T_{r}-T_{e}\right|\right) \\
C 2=f_{c}^{\prime}\left(\left|L_{r}-L_{e}\right|\right) \\
E=f_{e}^{1}\left(\left|T_{e}-T_{\text {init }}\right|\right)+f_{e}^{2}\left(\left|T_{e}-T_{\text {out }}\right|\right)+f_{e}\left(\left|L_{e}-L_{0}\right|\right)
\end{array}\right.
$$

According to the nature of the function can analyse the system energy saving strategies and control methods.

\section{Energy saving strategy}

According to the model, based on the thought of people-oriented, take customer satisfaction as a starting point, the maximum energy-saving potential of mining system, made the energy-saving control strategy.

Assuming that the entire indoor space is divided into $\mathrm{M}$ area, the number of users for $\mathrm{N}$, there are $\mathrm{M}_{\mathrm{i}}$ people in the first $\mathrm{i}$ area of $\mathrm{M}$ area.

$$
C 1=\frac{\sum_{i=0}^{n} C_{1 i}}{n}=\frac{\sum_{i=0}^{m}\left[\sum_{j=0}^{m_{i}} f_{c}\left(\left|T_{s i}-T_{s j}\right|\right)\right]}{n}
$$

$\mathrm{T}_{\mathrm{si}}$ is a setting parameter in the first $\mathrm{I}$ area, $\mathrm{T}_{\mathrm{ej}}$ is the first $\mathrm{J}$ individuals desired temperature. 
Without the case of the divided area can be seen as the set of the target temperature $T_{\mathrm{s}}$ in the divided areas, equation (8) can be modified as follows:

$$
C 1^{\prime}=\frac{\sum_{i=0}^{n} C_{i}}{n}=\frac{\sum_{i=0}^{m}\left[\sum_{j=0}^{m_{i}} f_{c}\left(\mid T_{s i}-T_{g}\right)\right]}{n}
$$

For the I-th region, we can always find a $\mathrm{T}_{\mathrm{SI}}$ satisfy $\sum_{j=0}^{m_{i}} f_{c}\left(\left|T_{s i}-T_{e j}\right|\right) \leq \sum_{j=0}^{m_{i}} f_{c}\left(\left|T_{s i}-T_{g}\right|\right)$, then $\frac{\sum_{i=0}^{m}\left[\sum_{j=0}^{m_{i}} f_{c}\left(\left|T_{s i}-T_{s j}\right|\right)\right]}{n} \geqslant \frac{\sum_{i=0}^{m}\left[\sum_{j=0}^{m_{i}} f_{c}\left(\left|T_{s i}-T_{g}\right|\right)\right]}{n}$, namely $\mathrm{C} 1 \geqslant \mathrm{C} 1$, at the same time $\mathrm{T}_{\mathrm{s} 0}=\mathrm{T}_{\mathrm{s} 1}=$ $\mathrm{T}_{\mathrm{s} 2}=\ldots \ldots=\mathrm{T}_{\mathrm{sm}}$. Obviously, subregional personalize adjusted in most cases can improve user satisfaction. For energy consumption, unless the structure of a single user groups makes Tout and Ts always too large tends to lead to increased energy consumption, otherwise under normal circumstances, the target temperature set by region in Tsi uniform distribution around the set temperature Ts, under synthesis conditions, does not lead to significant increase in energy consumption. Impact of lighting and air-conditioning is similar.

\section{Hardware system solutions}

According to intelligent building hardware conditions for the realization of energy-saving strategies, this paper shows a typical hardware environment, namely hardware system consists of sensors, air conditioning, lighting, shutters, windows, whose structure shown in Fig.1.

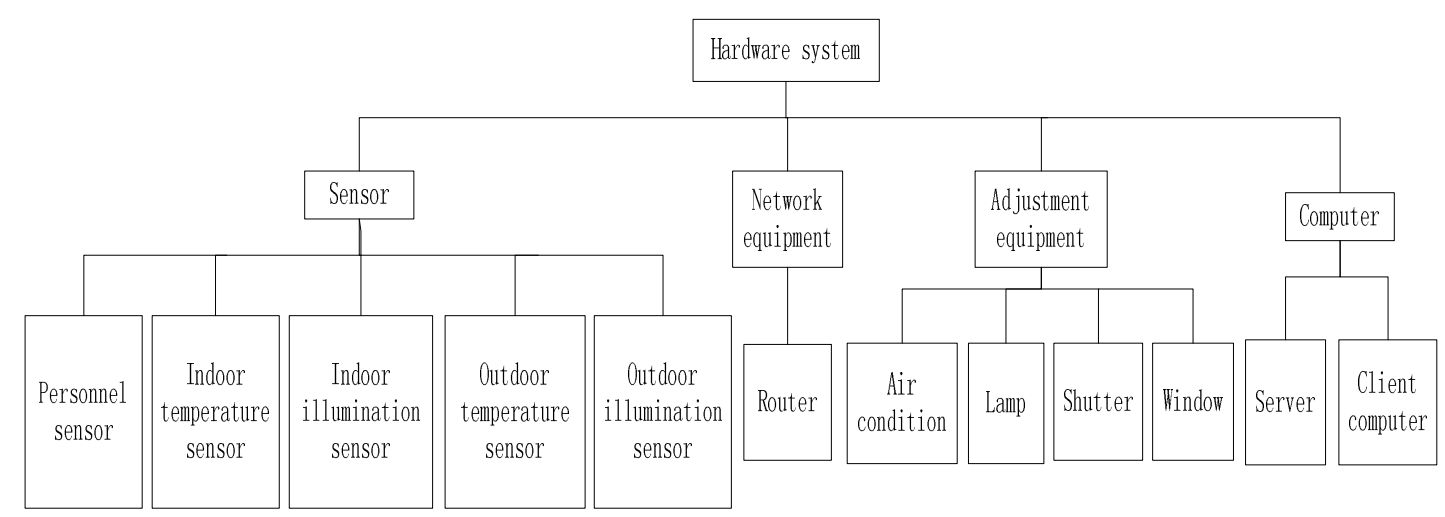

Fig.1: Hardware system structure

The large building air conditioning always uses central air conditioning system. The system uses the air conditioning itself can't be precise temperature control. There are low, medium and high grade to choose power. The system software is based on the temperature sensor data as the basis for air conditioning to achieve precise control of temperature. The system also uses a controllable switch window, so that software can control the indoor and outdoor air exchange. Illumination, light output can be adjusted in the range of $0 \sim 100 \%$, the shutter can be lifting, rotating angle, thereby regulating the amount of outdoor light. The computer system includes the server and the client computer, server to realize the data acquisition, transmission, storage, and control to every intelligent device, the client computer using client software to interact with the system. The hardware is connected via a router, through the OPC [7, 8] control server to each sensor and equipment.

\section{Energy saving control program design}

System control method shown in Fig.2. In this process, the central controller (server) reads the current outdoor and indoor environmental parameters, combined with the season, time, and device status comparison indoor and outdoor environments, to obtain shutters, window control scheme utilizes the natural conditions of the apparatus; combined with the season, time, and device status 
comparison indoor and outdoor environments and user set parameters, to obtain air conditioning, lighting control scheme

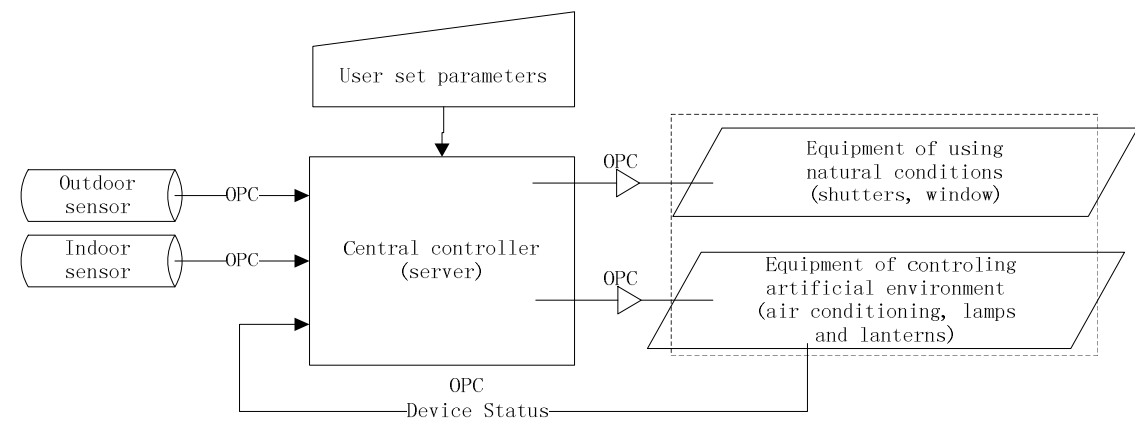

Fig.2: System control method

The parameters set by the user are a dynamic process in real time and parallel with automatic process of the system adjustment, then input to the central controller via the network.

\section{Temperature adjustment}

Temperature-related parameter comprises the basic set temperature, the temperature of individual fine-tuning, the maximum overshoot and the season, time, parameter variation caused by whether a man exists in the room. The target temperature for $T_{t}$, the basic set temperature for $T_{b}$, personalized fine-tuning temperature of $\mathrm{T}_{\mathrm{p}}$, seasons, time, and people or not factor lead to parameter variation for $T_{d}$, the calculation formula of target temperature $T_{b}$ as shown in equation (10).

$$
\mathrm{T}_{\mathrm{t}}=\mathrm{T}_{\mathrm{b}}+\mathrm{T}_{\mathrm{p}}+\mathrm{T}_{\mathrm{d}}
$$

The basic temperature is set by the administrator. In order to prevent frequent start-conditioned and closed, allowing the temperature adjustment has some overshoot The larger temperature, the faster rebound. So the overshoot should change with indoor and outdoor temperature varies. Overshoot may be set to $0.5 \sim 1.5{ }^{\circ} \mathrm{C}$. Assuming that the overshoot for $\mathrm{T}_{\text {over }}$, outdoor temperature for $\mathrm{T}_{\text {out }}$, indoor temperature for $\mathrm{T}_{\text {in }}$, overshoot maximum limit for $\mathrm{T}_{\max }$, overshoot minimum limit for $\mathrm{T}_{\min }$, the limit of the outdoor temperature for $\mathrm{T}_{\text {lim }}$ (minimum and maximum temperature of the year), overshoot is calculated as in formula (11).

$$
\mathrm{T}_{\text {over }}=\left(\mathrm{T}_{\max }-\mathrm{T}_{\min }\right) \times\left(\mathrm{T}_{\text {out }}-\mathrm{T}_{\text {in }}\right) /\left|\mathrm{T}_{\text {lim }}-\mathrm{T}_{\text {in }}\right|
$$

\section{Illumination adjustment}

Assuming that target illumination for $\mathrm{B}_{\mathrm{t}}$, the basic illumination for $\mathrm{Bb}$, personalized fine-tuning illumination for $B_{p}$, the parameter variation caused by time and people for $B_{d}$, the calculation formula of target illumination $\mathrm{Bt}$ in formula (12):

$$
\mathrm{B}_{\mathrm{t}}=\mathrm{B}_{\mathrm{b}}+\mathrm{B}_{\mathrm{p}}+\mathrm{B}_{\mathrm{d}}
$$

The basic illumination $B_{d}$ can be located within $300 \sim 500$ Lux, this system is set 400Lux. Personalized trimming illumination $B_{p}$ is set by the user, if not set, it defaults to 0 . $B_{d}$ is the parameter variation of time and people, if no people in room it is set $-\infty$, and non-working time is negative.

The shutter adjustment is mainly based on outdoor light and indoor illumination. Specific principles as follows:

i) When working hours during the day, illumination is higher. When outdoor dazzling brightness too high for comfortable, should pull down blinds; if not dazzling, it should pull the blinds to increase natural light. 
ii) When the shutter is pulled down state, angle is adjustable. At lower indoor brightness, increase the angle, increase the amount of light transmission; At higher indoor brightness, reduce the angle and reduce the amount of light transmission.

iii) Non-working time usually at or near the evening, heat dissipation is mainly caused by radiation effects. Indoor to outdoor radiation is stronger, results in the decrease of indoor temperature.

\section{System works}

\section{Satisfaction Result}

The auto adjustment program to draw in indoor temperature and indoor illuminance curves are shown in Fig.3 and Fig.4 respectively. 8:00 to 17:00 is working hours, other times is non-working hours. Fig.3 between about 19:00 and 20:00 and 21:00 the temperature curve drops more obvious, showing the adjusted non-working time someone conducted. Fig.4 is also clearly shows the influence of illumination.

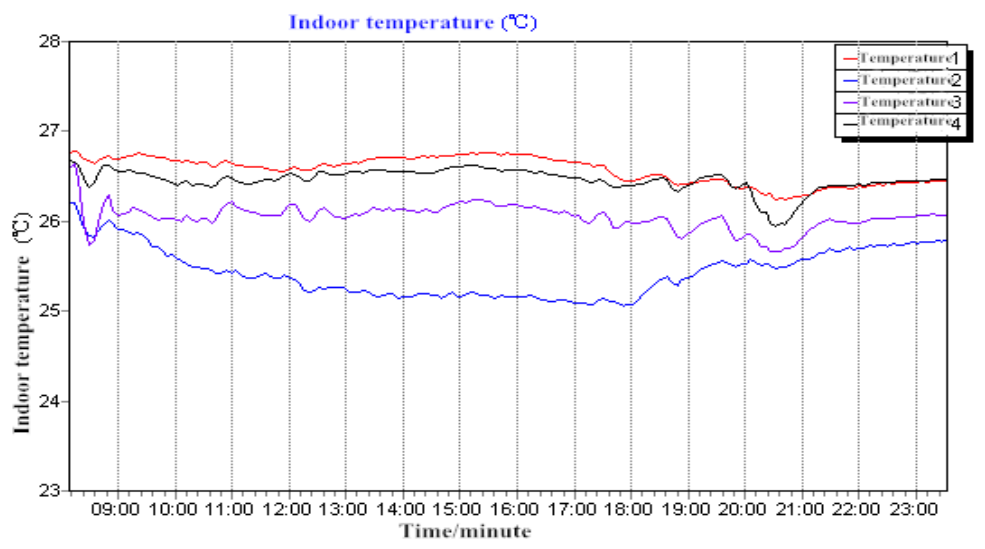

Fig.3: Temperature curves

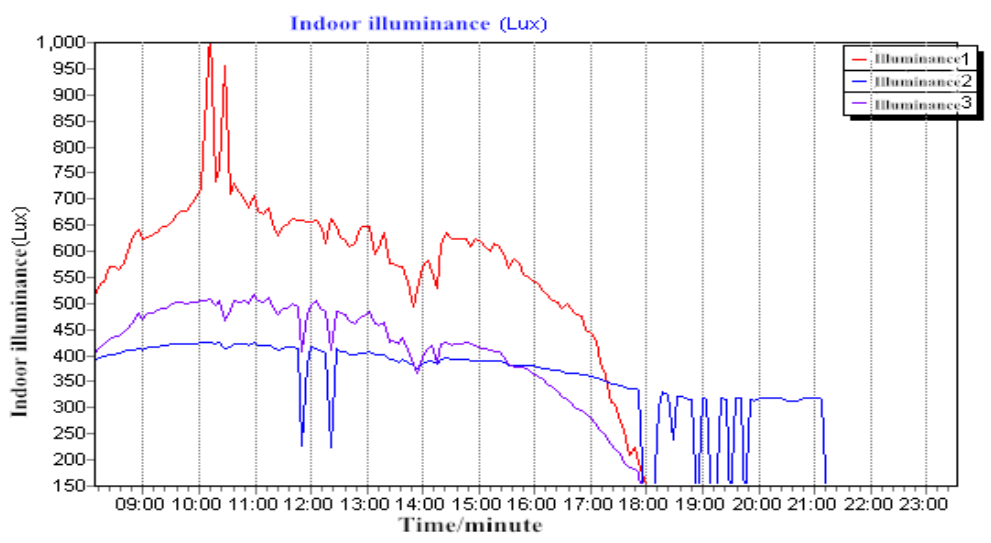

Fig.4: Luminance curves

Energy-saving Result

Without using this system for energy-saving control, consumption data is shown in Table 1, and using this system energy consumption data is shown in Table 2.

Table 1: Power consumption in manual mode

\begin{tabular}{lllll}
\hline Date & $\begin{array}{l}\text { Lighting energy } \\
\text { consumption }\end{array}$ & $\begin{array}{l}\text { Air } \\
\text { conditioning } \\
\text { energy } \\
\text { consumption }\end{array}$ & $\begin{array}{l}\text { Total energy } \\
\text { consumption }\end{array}$ & $\begin{array}{l}\text { Average } \\
\text { outdoor temperature }\end{array}$ \\
\hline $8-15$ & 12.8 & 126.8 & 139.6 & 24 \\
$8-17$ & 12.7 & 91.8 & 104.5 & 24 \\
$8-18$ & 14.8 & 65.4 & 80.2 & 26 \\
$8-19$ & 13.6 & 85.7 & 99.3 & 25 \\
\hline
\end{tabular}


Table 2: Power consumption in automatic mode

\begin{tabular}{lllll}
\hline Date & $\begin{array}{l}\text { Lighting energy } \\
\text { consumption }\end{array}$ & $\begin{array}{l}\text { Air } \\
\text { conditioning } \\
\text { energy } \\
\text { consumption }\end{array}$ & $\begin{array}{l}\text { Total energy } \\
\text { consumption }\end{array}$ & $\begin{array}{l}\text { Average } \\
\text { outdoor temperature }\end{array}$ \\
\hline $8-22$ & 11 & 94.6 & 105.6 & 26 \\
$8-23$ & 11.2 & 49.2 & 60.4 & 26 \\
$8-24$ & 9.4 & 68 & 77.4 & 24 \\
$8-25$ & 16.7 & 51.9 & 68.6 & 24 \\
\hline
\end{tabular}

Manual adjustment, the average daily consumption of $105.9 \mathrm{KWh}$; Automatic adjustment, average daily consumption of $78.0 \mathrm{KWh}$, the energy consumption is reduced by $26.3 \%$.

\section{Conclusion}

This paper analyzes the indoor and outdoor environment parameters influence on customer satisfaction and system energy consumption, the indoor and outdoor temperature, illumination and user set values for the parameters, the establishment of a comprehensive mathematics to user satisfaction and energy consumption as the goal of the model, proposed energy-saving control strategy, through subregional achieve a personalized intelligent control, combined with different time period of people for the integrated control of air conditioning and lighting, and the use of windows and shutters control introduce favorable external conditions for the natural environment, providing convenient and practical manual control supplement. This is the basic design of energysaving control system. The results show that the system can meet the need of users, as well as lower energy consumption, and achieve great results.

\section{References}

[1] Lee,W.L. and Yik,F.W.H. Regulatory and voluntary approaches for enhancing building energy efficiency.Progress in Energy and Combustion Science.30(5), pp.477-499,2004

[2] Taojin Gu,Yingxin Zhu,Lijing Gu. China building life cycle environmental impact assessment . Tsinghua University (Natural Science).2006(12)

[3] Kujuro, A.A building automation system for intelligent buildings.Japan Telecommunications Review.1988(1)

[4] Guangyuan Huang. Energy-efficient air-conditioning control systems in large buildings. System Engineering Theory and Practice.1993(05)

[5] Xueli Zhu, Weigui Qi,Yajun Lu. Strategies for building heating load forecasting and predictive control. Control and Decision.2002(S1)

[6] Xu Zhang, Suilin Wang. Energy Consumption Research and Energy Saving Potential Analysis for an Office Building Air Conditioning System. The First International Conference on Building Energy and Environment.2008

[7] Han Changho, Oh Choonsuk, Ryu Youngkee. An implementation of OPC client for display inspection system. Journal of Institute of Control, Robotics and Systems. 14(5), pp.411-414, 2008

[8] Jinxue Xu, Hongwu Hu, Yumei Liu. Remote Monitoring System Based on OPC technology solutions . Shenyang University of Technology. 2007(05) 